\title{
О фундаменталистском и социокультурном направлениях в современной отечественной и западной философии математики
}

\author{
Побережный И.А. \\ Курский государственный университет, \\ Россия, 305000, г. Курск, ул. Радищева, 33 \\ E-mail: ivan.poberezhnyy@gmail.com
}

\begin{abstract}
Аннотация. К концу прошлого столетия в философии математики значительно расширился круг проблем, увеличилось число научных публикаций и сформировались два противостоящих друг другу направления: фундаменталистское и нефундаметналистское (социокультурное). Представители первого утверждают априорность природы математических объектов и понятий, онтологическую объективность математики. Сторонники социокультурного подхода утверждают возможность наличия множественности математик, зависимость математической парадигмы от исторических и социально-культурных факторов. Автором рассмотрены особенности каждого направления, вопросы и проблемы, вызывающие наибольшие разногласия. Наличие различных подходов к решению какой-либо проблемы имеет большой потенциал, так как способствует процессу развития научной области и расширению ее границ.
\end{abstract}

Ключевые слова: философия математики, фундаментализм, антифундаментализм, парадигма, постпозитивизм

Для цитирования: Побережный И.А. 2021. О фундаменталистском и социокультурном направлениях в современной отечественной и западной философии математики. NOMOTHETIKA: Философия. Социология. Право, 46 (2): 223-229. DOI 10.52575/2712-746X-2021-46-2-223-229

\section{About fundamentalist and sociocultural streams in modern russian and western philosophy of mathematics}

\author{
Ivan A. Poberezhnyi \\ Kursk State University, \\ 33 Radishchev St, Kursk, 305000, Russia \\ E-mail: ivan.poberezhnyy@gmail.com
}

\begin{abstract}
By the end of the twentieth century, the range of problems in the philosophy of mathematics has significantly expanded, the number of scientific publications has increased, and two opposing trends have emerged - the fundamentalist and non-fundamentalist (socio-cultural). Representatives of the first claim a priori nature of mathematical objects and concepts, ontological objectivity of mathematics. Proponents of the socio-cultural approach assert the possibility of a plurality of mathematics, the dependence of the mathematical paradigm on historical and socio-cultural factors. The article considers the features of each direction, and considers the issues and problems that cause the most controversy. The presence of different approaches to solving any problem has a great positive potential, as it contributes to the development of the scientific field and the expansion of its borders.
\end{abstract}

Key words: philosophy of mathematics, fundamentalism, anti-fundamentalism, paradigm, Postpositivism.

For citation: Poberezhnyi I.A. 2021. About fundamentalist and sociocultural streams in modern russian and western philosophy of mathematics. NOMOTHETIKA: Philosophy. Sociology. Law series, 46 (2): 223-229 (in Russian). DOI 10.52575/2712-746X-2021-46-2-223-229 
На протяжении прошлого столетия круг проблем философии математики, как западной, так и отечественной, значительно расширяется. Если изначально она была связана с проблемой обоснования математического знания, то в дальнейшем в ее круг входят онтологические и гносеологические проблемы осмысления сущности математики, природы математических объектов и понятий, природы доказательства в математике, соотношения математики и логики, проблема построения «приемлемых онтологических моделей» [Арепьев, 2014] математических объектов, проблема сущности бесконечности и другие.

К концу XX столетия регулярное проведение конференций и семинаров по философии математики в России повышает исследовательскую активность специалистов. Увеличивается количество научных публикаций, монографий и сборников, и в философии математики обнаруживаются два различных, противостоящих друг другу направления: фундаменталистское и нефундаметналистское, получившее название социокультурного. Конечно же, возникли эти направления несколько раньше и не в одно время, о чем будет сказано ниже, но их противостояние обнаруживается ближе к концу прошлого века. Рассмотрим основные особенности каждого из этих направлений в современной отечественной и западной философии математики.

Под фундаментализмом в философии науки понимают такую эпистемологическую позицию, «с которой выдвигается идеал обоснованности научного знания и критерий обоснованности знания как критерий его (знания) научности» [Антаков, 2007, с. 302].

Представители фундаменталистского направления философии математики утверждают, что математика принципиально едина, что математическая парадигма, включающая в себя объект познания и методы исследования, в основе своей неизменна, а теоретическая математика опирается на классическую логику. На протяжении длительного времени математика представлялась исследователям наукой, которая свободна от социокультурных ценностей и факторов. Академическая математика, обладающая высоким уровнем абстрактности, считалась упорядоченной системой обоснованного и непротиворечивого знания, которое имеет универсальный характер. Природа математических объектов и понятий априорна, из чего следует онтологическая объективность математики. Математические доказательства, опирающиеся на законы логики, обладают необходимой степенью надежности. В философии математики фундаментализм - это направление, «которое подчиняет исследование математики одной целевой установке - выяснению проблемы сущности математики, не зависящей от ее конкретных исторических состояний» [Барабашев, 2001, с. 79].

Внимание сторонников фундаментализма сосредоточено на гносеологических вопросах и классической проблематике обоснования математического знания, исследовании природы и сущности математики как таковой. Развитие математики с этой позиции представляет собой процесс, устремленный к некоторому заданному идеалу и который сам по себе является исторической необходимостью.

Сторонники нефундаменталистского (социокультурного) подхода к математическому познанию утверждают возможность наличия множественности математик, зависимость математической парадигмы от исторических и социально-культурных факторов. Они считают, что при изучении математических представлений необходимо изучать и ту среду, в которой эти представления возникли и существуют, так как их смысл определяется контекстом, в котором они употребляются. По их мнению, такой подход способствует тому, «чтобы увидеть разнообразие существующих путей развития человеческого мышления и осознать степень его вариативности» [Яшин, 2016, с. 67].

Классические работы по философии математики в основном было бы логично отнести к ее фундаменталистскому направлению. В этих работах рассматриваются, как правило, проблемы оснований математического знания, онтологические и гносеологические проблемы математики, и в них не затрагиваются вопросы развития математики как науки. Фундаменталистская философия математики занимается, прежде всего, осмыслением сущности математики, формой существования её объектов. Она связана с философией математики 
И. Канта, классическими программами обоснования математического знания конца XIX начала XX века Б. Рассела, Л.Э. Брауэра и Д. Гильберта (логицизм, интуиционизм, формализм) [Побережный, 2019], программой нахождения фундаментальных математических структур, которая была предложена группой французских математиков Бурбаки, более поздними исследованиями природы математических объектов, изложенными в работах П. Мэдди, У. Куайна, Х. Патнэма и их приверженцев. Не менее широко представлено это направление в отечественной философии математики. К числу его представителей можно отнести таких известных ученых, как А.Д. Александров, А.Н. Колмогоров, В.Я. Перминов, А.Г. Рузавин и другие. С точки зрения представителей данного направления, математика представляет собой систему знаний, развитие которой «является исторической необходимостью, предопределяющей стремление математики к некоторому заранее заданному идеалу» [Яшин, 2016, с. 62].

В своей книге «Будущее математики: методологические аспекты прогнозирования» А.Г. Барабашев замечает, что в современной западной фундаменталистской философии математики можно увидеть «поворот от чисто аналитических концепций сущности математики к тем или иным вариантам эмпирических "синтетических" представлений» [Барабашев, 2001, с. 82] Современные западные ученые заняты проблемой реальности математических объектов и поиском аналогий между истинностью естественнонаучного и математического знания. Рассматривается вопрос о том, какова онтологическая реальность понятия числа, если оно не имеет никаких других свойств, кроме свойства упорядоченности. [Арепьев, 2014] И, наконец, Х. Патнэм считает, что в математических доказательствах могут быть использованы не только дедуктивые, но и индуктивные умозаключения, которые следуют из тривиальных математических фактов. Фундаменталистское направление имеет достаточно большое число сторонников среди авторитетных ученых, представителей философии математики. Однако уже к концу прошлого столетия число их оппонентов, сторонников социокультурного направления, стало возрастать.

Социокультурное направление философии математики формируется позже, примерно в середине 60-х годов XX века. В.А. Шапошников связывает формирование альтернативы фундаментализму с возникновением и постепенным укреплением позиций постпозитивистской философии науки, стремительным развитием компьютерной техники и цифровых технологий. Все это, по мнению В.А. Шапошникова, приводит к тому, что путь, пройденный философией математики за полвека (1930-1970-е годы) сам становится предметом философского исследования. В результате этого исследования «было декларировано появление... альтернативного направления» [Шапошников, 2018, с. 48]. Исследовательский интерес его представителей нацелен не на изучение оснований математического знания и стандартов математических рассуждений, а на исследование реальных путей развития математического знания, на поиск общих схем и закономерностей развития математики. «Работы нефундаменталистского направления претендуют на постановку и решение проблем выявления концепций развития математики, поиска схем этого развития» [Барабашев, 2001, c. 84].

В рамках нефундаменталистского направления большое значение придается исследованию процесса развития математики как социокультурного явления, то есть сама «сущность математики здесь предстает как закономерности ее развития» [Барабашев, 2001, c. 84]. Иными словами, при изучении развития математики как науки подчеркивается необходимость учета всего многообразия социокультурных факторов. Исследования по истории математики показывают, что сам процесс развития во многих случаях существенно определяется внешним культурным и социальным окружением. Попытки дать адекватную картину этого процесса и влияния на него внешних факторов имеют место в работах как ведущих отечественных специалистов в данной области, так и зарубежных ученых, работы которых широко публикуются в известных математических изданиях. 
В западной философии математики одной из первых значительных работ социокультурного направления стала книга И. Лакатоса «Доказательства и опровержения. Как доказываются теоремы», в которой ученый стремится показать общую схему процесса развития математики, рассматривая историю доказательств теоремы Л. Эйлера о соотношении числа граней, вершин и ребер в многогранниках. В современной западной философии науки производится поиск моделей, описывающих процесс развития математической науки как элемента социокультурной системы. Так, Р. Уайлдер в работе «Математика как культурная система» [Wilder R., 1981] описывает математику как отдельную область культуры, и формирует свою схему исторического взаимодействия разделов математики. При этом разделение математики как культурной системы на элементы не всегда совпадает с ее обычным разделением на ряд теоретических дисциплин.

Одной из известных работ, в которой дается анализ динамики математического знания, стала работа американского философа Ф. Китчера «Природа математического знания» [Kitcher Ph., 1984]. В ней Ф. Китчер попытался связать проблемы обоснования математики с проблемой научной рациональности. При этом он стремился учитывать различные социокультурные факторы, которые обусловливают диалектические процессы математики как научной дисциплины. Автор строит эмпирическую концепцию сущности математической науки и развития системы математического знания как процесса деятельности научного сообщества в роли коллективного субъекта научного познания.

Можно утверждать, что представителям нефундаменталистского направления удалось значительно расширить границы философии математики. На современном этапе еще одной важной проблемой и областью рефлексии становится вопрос применения математических результатов. Сюда входят, прежде всего, вопросы прикладной математики. Появляются утверждения о том, что наиболее адекватное представление о природе математического знания можно получить, исследуя именно феномен прикладной математики в качестве исходного [Mathematics, 1984; New Directions, 1985].

В отечественной философии математики к нефундаменталистскому направлению можно отнести исследования большого числа известных ученых. В их работах просматривается стремление найти диалектику в самом процессе развития математики как системы научного знания, а не в ее сущностных характеристиках, рассматриваемых вне связи с другими областями знания. В них отсутствует стремление установить вневременную, не зависящую от исторического контекста сущность математики. М.И. Панов утверждает, что математическая наука включена «в общекультурный контекст человеческой деятельности» [Панов, 2003, 15] и предрассудком является мнение о том, что «объективированная интерпретация науки гарантирует, что любое открытие может быть повторено».

А.Г. Барабашев замечает, что нефундаменталистские работы занимают все большее место в литературе по философии математики. Сюда относятся исследования проблем интуиции, проблем сущности математического доказательства как исторически эволюционирующих процессов. Интерес к нефундаменталистским работам по философии математики, пишет ученый, выражен гораздо отчетливее, чем к исследованиям традиционной фундаменталистской направленности.

Несмотря на очевидную популярность, социокультурный подход в философии математики остается далеко не бесспорным. Даже убежденные сторонники этого подхода признают, что нет достаточных оснований для допущения культурного релятивизма в области математики. В.В. Целищев считает, что «признание математики просто человеческой активностью, с точки зрения гуманистической математики, вообще не имеет отношения к философии математики. Последняя усматривает скрытый смысл за пределами социально-историко-культурного контекста, который проявляется в неизменной онтологии математических объектов и вневременном характере математических истин» [Целищев, 2002, с. 45].

Представители же фундаментализма в данном вопросе гораздо более категоричны. Так, Е.М. Вечтомов, убежденный сторонник фундаменталистской философии математики, 
в монографии «Метафизика математики» пишет: «Если фундаментализм отображает подлинную онтологию математики, то нефундаментализм навязывает нам рекламу внематематических декораций, приукрашенных элементами современного дизайна» [Вечтомов, 2006, с. 117]. Ученый, рассмотрев основные вехи истории математики, приходит к выводу, что «другой математики быть не могло» [Вечтомов, 2006, с. 113].

В.Я. Перминов также достаточно критически относится к большинству тезисов антифундаментализма. Ученый считает, что развитие науки представляет собой «процесс очищения нормативных предпосылок от всякого рода ценностных и социокультурных аспектов» [Перминов, 1999, с. 245]. В другой работе он пишет: «Математика очищает себя от ошибок... посредством системности теории» [Перминов, 2001, с. 73]. Научная теория, считает ученый, в процессе своего вызревания в итоге полностью исключает из себя всякое социокультурное и историческое содержание. Это означает, что в конечном счете необходимо полностью отказаться от связи обоснования науки с культурными универсалиями. «Наука по своим основаниям несравненно более фундаментальна, чем культура» [Перминов, 1999, с. 245]. Зрелая наука базируется на фундаменте, который внеисторичен. В частности, математика фиксирует в своих представлениях порожденные деятельностью структуры мышления, поэтому математическое знание обладает высокой исторической стабильностью. Ничто в математике не доказывает неопределенности ее базовых структур.

Для обоснования математики необходима функциональная позиция, которая выявляла бы априорные формы мышления. «Если бы все человечество потеряло на время память и прервало все исторические эстафеты, то, возродившись к жизни, оно неизбежно бы воспроизвело реальную логику, арифметику, евклидову геометрию и абстрактную онтологию в том же самом виде, ибо эти структуры поддерживаются не в силу традиции, но под давлением функции», - утверждает В.Я. Перминов [1999, с. 249] Даже в истории математики ученый считает социокультурный подход неприемлемым подходом к изучению ее философских оснований, поскольку при таком подходе несущественной становится сама преемственность математических структур. При этом В.Я. Перминов никоим образом не считает этот подход излишним или несущественным, так как он позволяет получить объяснение определенного рода событий в истории математики, зависящих от внешних условий и не выводимых из внутренней логики науки. Суть в том, что этот подход «вторичен и сам по себе не может претендовать ни на статус особой философии математики, ни, тем более, на некоторое перспективное направление в философии математики», - считает ученый [1999, с. 249]

Следует заметить, что у многих современных авторов есть работы как фундаменталистской, так и нефундаменталистской направленности. В последних рассматривается историческое развитие математического знания как диалектический процесс взаимодействия эмпирического и умозрительного уровней математического исследования, рассматриваются различные типы взаимодействия философии и математики.

На наш взгляд, наличие различных подходов к решению какой-либо проблемы всегда имеет большой потенциал, поскольку способствует диалектическому процессу развития науки, позволяет значительно расширить ее границы.

Таким образом, споры между сторонниками фундаментализма и антифундаментализма в философии математики продолжаются как в среде западных, так и в среде отечественных ученых. Как правило, в большинстве научных споров оппоненты остаются при своих мнениях, усиливая свои аргументы и укрепляя научные позиции. Любой спор является следствием существенных различий в восприятии реальности, различий исследовательских успехов сторон. Как показывает историческая практика, любая логически выдержанная и исследовательски плодотворная научная позиция всегда найдет своих сторонников. 


\section{Список литературы}

1. Арепьев Е.И. 2014. Природа чисел в свете расширенной трактовки действительности. Российский гуманитарный журнал, 3 (4): 229-236.

2. Антаков С.М. 2007. Фундаментализм и его отрицания в философии науки (наука как предмет философии). Вестник Нижегородского университета им. Н.И. Лобачевского. Социальные науки, 1: 301-307.

3. Барабашев А.Г. 1991. Будущее математики: методологические аспекты прогнозирования. М., Изд-во МГУ, 160 с.

4. Вечтомов Е. М. 2006. Метафизика математики. Киров: Изд-во ВятГГУ, 508 с.

5. Панов М.И. 2003. Философия математики XX века (Обзор). В кн.: Философия в XX веке. В 2-х частях: Ч. 2. Социальные и гуманитарные науки в XX веке. М., Институт научной информации по общественным наукам РАН: 11-39.

6. Перминов В.Я. 1999. Ложные претензии социокультурной философии науки. Стили в математике: социокультурная философия математики. СПб., РХГИ: 235-253.

7. Перминов В.Я. 2001. Философия и основания математики. М., Прогресс-Традиция, 320 с.

8. Побережный И.А. 2019. Интуиция в математике: от интуитивизма А. Пуанкаре к интуиционизму Л. Брауэра и Г. Вейля. Философская мысль, 5: 1-6.

9. Целищев В.В. 2002. Философия математики. Ч. 1. Новосибирск: Наука, 212 с.

10. Шапошников В.А. 2018. Философия математики в эпоху перемен: поворот к математической практике и ориентация на приложения. В кн. История и философия науки в эпоху перемен. М., Изд-во «Русское общество истории и философии науки»: 47-49.

11. Яшин Б.Л. 2016. Социокультурные аспекты математического познания и этноматематика. Педагогика и просвещение, 1: 60-70.

12. Kitcher Ph. 1984. The nature of mathematical knowledge. N.Y., 368 p.

13. Mathematics: People, Problems, Results. Vol. 3. 1984.Wadsworth International Inc., Brigham Young Univ., 312 p.

14. New Directions in the Philosophy of Mathematics: An Antology. 1985. Boston etc., Birkhäuser, $323 \mathrm{p}$.

15. Wilder R. 1981. Mathematics as a Cultural System. Oxford, 194 p.

\section{References}

1. Arep'yev Ye.I. 2014. Priroda chisel v svete rasshirennoy traktovki deystvitel'nosti [The nature of numbers in the light of the expanded interpretation of reality]. Rossiyskiy gumanitarnyy zhurnal, 3 (4): 229-236.

2. Antakov S.M. 2007. Fundamentalizm i yego otritsaniya v filosofii nauki (nauka kak predmet filosofii) [Fundamentalism and its denials in the philosophy of science (science as a subject of philosophy)]. Vestnik Nizhegorodskogo universiteta im. N.I. Lobachevskogo. Sotsial'nyye nauki, 1: 301-307.

3. Barabashev A.G. 1991. Budushcheye matematiki: metodologicheskiye aspekty prognozirovaniya [The Future of Mathematics: Methodological Aspects of Forecasting]. M., Publ. MGU, 160 p.

4. Vechtomov Ye. M. 2006. Metafizika matematiki [The Future of Mathematics: Methodological Aspects of Forecasting]. Kirov, Publ. VyatGGU, 508 p.

5. Panov M.I. 2003. Filosofiya matematiki XX veka (Obzor). [Philosophy of Mathematics of the XX century (Review)]. In: Filosofiya $v$ XX veke [Philosophy in the XX century]. In 2 parts: Part 2. Sotsial'nyye i gumanitarnyye nauki v XX veke. [Social and humanitarian sciences in the XX century]. M., Publishing House Institute of Scientific Information on Social Sciences of the Russian Academy of Sciences: $11-39$.

6. Perminov V.YA. 1999. Lozhnyye pretenzii sotsiokul'turnoy filosofii nauki [False Claims of the Sociocultural Philosophy of Science]. Stili v matematike: sotsiokul'turnaya filosofiya matematiki. SPb., Publ. RKHGI: 235-253.

7. Perminov V.YA. 2001. Filosofiya i osnovaniya matematiki [Philosophy and Foundations of Mathematics]. M., Publ. Progress-Traditsiya, 320 p.

8. Poberezhnyy I.A. 2019. Intuitsiya v matematike: ot intuitivizma A. Puankare k intuitsionizmu L. Brauera i G. Veylya [Intuition in mathematics: from the intuitionism of A. Poincare to the intuitionism of L. Brouwer and G. Weil]. Filosofskaya mysl', 5: 1-6. 
9. Tselishchev V.V. 2002. Filosofiya matematiki [Philosophy of Mathematics]. Ch. 1. Novosibirsk, Publ. Nauka, 212 p.

10. Shaposhnikov V.A. 2018. Filosofiya matematiki v epokhu peremen: povorot k matematicheskoy praktike i oriyentatsiya na prilozheniya [The Philosophy of Mathematics in an Age of Change: A Turn towards Mathematical Practice and an Application Orientation]. In: Istoriya i filosofiya nauki v epokhu peremen. M., Publ. Russkoye obshchestvo istorii i filosofii nauki: 47-49.

11. Yashin B.L. 2016. Sotsiokul'turnyye aspekty matematicheskogo poznaniya i etnomatematika [Socio-cultural aspects of mathematical knowledge and ethnomatics]. Pedagogika i prosveshcheniye, 1: 60-70.

12. Kitcher Ph. 1984. The nature of mathematical knowledge. N.Y., 368 p.

13. Mathematics: People, Problems, Results. Vol. 3. 1984.Wadsworth International Inc., Brigham Young Univ., $312 \mathrm{p}$.

14. New Directions in the Philosophy of Mathematics: An Antology. 1985. Boston etc., Birkhäuser, $323 \mathrm{p}$.

15. Wilder R. 1981. Mathematics as a Cultural System. Oxford, 194 p.

\section{СВЕДЕНИЯ ОБ АВТОРЕ}

Побережный Иван Александрович, аспирант кафедры философии Курского государственного университета, Курск, Россия

\section{INFORMATION ABOUT THE AUTHOR}

Ivan A. Poberezhny, $\mathrm{PhD}$ student, Department of Philosophy, Kursk State University, Kursk, Russia 